\title{
Two in one sweep: aluminum tolerance and grain yield in P-limited soils are associated to the same genomic region in West African Sorghum
}

Willmar L Leiser ${ }^{1,2 *}$, Henry Frederick W Rattunde ${ }^{2}$, Eva Weltzien ${ }^{2}$, Ndiaga Cisse ${ }^{3}$, Magagi Abdou ${ }^{4}$, Abdoulaye Diallo ${ }^{5}$, Abocar O Tourè ${ }^{5}$, Jurandir V Magalhaes ${ }^{6}$ and Bettina IG Haussmann ${ }^{1}$

\begin{abstract}
Background: Sorghum (Sorghum bicolor L. Moench) productivity is severely impeded by low phosphorus (P) and aluminum (Al) toxic soils in sub-Saharan Africa and especially West Africa (WA). Improving productivity of this staple crop under these harsh conditions is crucial to improve food security and farmer's incomes in WA.

Results: This is the first study to examine the genetics underlying sorghum adaptation to phosphorus limitation in a wide range of WA growing conditions. A set of 187 diverse sorghum genotypes were grown in $29-\mathrm{P}$ and $+\mathrm{P}$ field experiments from 2006-2012 in three WA countries. Sorghum grain yield performance under $-P$ and $+P$ conditions was highly correlated $\left(r=0.85^{* * *}\right)$. Significant genotype-by-phosphorus interaction was detected but with small magnitude compared to the genotype variance component. We observed high genetic diversity within our panel, with rapid linkage disequilibrium decay, confirming recent sequence based studies in sorghum. Using genome wide association mapping based on 220934 SNPs we identified one genomic region on chromosome 3 that was highly associated to grain yield production. A major Al-tolerance gene in sorghum, SbMATE, was collocated in this region and SBMATE specific SNPs showed very high associations to grain yield production, especially under -P conditions, explaining up to $16 \%$ of the genotypic variance.
\end{abstract}

Conclusion: The results suggest that SWMATE has a possible pleiotropic role in providing tolerance to two of the most serious abiotic stresses for sorghum in WA, Al toxicity and P deficiency. The identified SNPs can help accelerate breeding for increased sorghum productivity under unfavorable soil conditions and contribute to assuring food security in WA.

Keywords: Sorghum, Phosphorus, Aluminum, Breeding, Genetics, West Africa

\section{Background}

Sorghum (Sorghum bicolor L. Moench) is a staple crop of the Savannah Zone of West- and Central Africa, where it is cultivated in low input cropping systems [1]. Limited $\mathrm{P}$ availability and aluminum (Al) toxicity in the soil are serious and frequent constraints to sorghum growth and productivity across sub-Saharan Africa, particularly in West Africa (WA) [2-4]. The adaptation of sorghum to these conditions is crucial for food

\footnotetext{
*Correspondence: willmar_leiser@uni-hohenheim.de

'Institute of Plant Breeding, Seed Science and Population Genetics, University of Hohenheim, Fruwirthstr. 21, 70599 Stuttgart, Germany

${ }^{2}$ International Crops Research Institute for the Semi-Arid Tropics, P 320,

Bamako, Mali

Full list of author information is available at the end of the article
}

security, and increasingly for farmer's income. Sorghum breeding specifically under P-limited conditions, carried out in WA since the last decade, was shown to be necessary and feasible to obtain superior genotypes for these conditions [5]. However, the genetic basis underlying grain yield performance under P-limited conditions in sorghum is not yet known. In contrast, breeding for Altolerance in sorghum has received much more attention and the underlying genetic mechanism has been identified. A gene in the multidrug and toxic compound extrusion (MATE) family, SbMATE, underlies the Alt $_{S B}$ locus on chromosome 3 , which is mainly responsible for Al-tolerance in sorghum via $\mathrm{Al}$-induced root citrate release [6]. Al-toxicity inhibits root growth and function, 
which leads to severe crop-yield losses [7]. Release of citrate and other organic anions into the rhizosphere prevents root damage by chelating $\mathrm{Al}^{3+}$. At the same time, citrate can mobilize $\mathrm{P}$ that is bound to soil clays by ligand exchange, dissolution and occupation of sorption sites, thus increasing $\mathrm{P}$ availability to the plants [8-10]. Hence, exudation of organic anions can lead to a higher $\mathrm{P}$ acquisition rate $[11,12]$. Recent work showed that over-expression of citrate synthesis and malate transporter genes in different species resulted in improved Al-tolerance and enhanced P uptake under low P conditions [13-15], supporting previous hypothesis that Altolerance and $\mathrm{P}$ uptake can be regulated by similar mechanisms [6]. However, in soybean and rape, citrate release is predominantly induced by $\mathrm{Al}$ and to a much lesser extent by low P conditions [16-19]. Evaluation of sorghum genotypes under P-limited and slightly Al-toxic soils, conditions common in WA, could shed light on the possible pleiotropic role of SbMATE in Al tolerance and P-efficiency and provide new possibilities for enhancing grain yield of sorghum under the prevalent low-input conditions in WA.

We provide the first evidence for a genetic and possible molecular link between Al-tolerance and P-efficiency, opening possibilities for the use of molecular breeding tools to facilitate development of cultivars with superior performance for poor WA soil conditions. We conducted an unprecedented evaluation of WA sorghum genotypes, with 187 West African genotypes assessed for grain yield in 15 low $\mathrm{P}(-\mathrm{P})$ and 14 P-fertilized $(+\mathrm{P})$ field experiments in Mali, Niger and Senegal from 2006-2012. Although fertilized, some of the $+\mathrm{P}$ fields showed also slight $\mathrm{P}$ limitations, due to the prevailing soil conditions in WA. The genetic architecture of grain yield under $-\mathrm{P}$ and $+\mathrm{P}$ conditions was investigated using both genome wide association mapping with 220934 SNPs, obtained by genotyping-by-sequencing (GBS), and gene specific markers associated with Al-tolerance within Alt $_{S B}$. Significant SNPs close to $(<40 \mathrm{~kb})$ and within $A l t_{S B}$ were associated to grain yield under P-limited conditions, suggesting that $A l t_{S B}$ has a pleiotropic role in providing tolerance to two of the most important abiotic constraints to sorghum productivity in WA, Al toxicity and P deficiency.

\section{Results}

Performance across $-\mathrm{P}$ and $+\mathrm{P}$ environments

Significant grain yield $(52 \%)$ and plant height $(22 \%)$ reduction and delayed heading (29\%) occurred under -P relative to the $+\mathrm{P}$ conditions. The individual $-\mathrm{P}$ sites had generally lower repeatabilities for grain yield than the $+\mathrm{P}$ sites (Additional file 1: Table S1) but broad sense heritability $\left(\mathrm{h}^{2}\right)$ computed across the $15-\mathrm{P}$ sites was slightly higher than for the $14+\mathrm{P}$ sites (Table 1), due to
Table 1 Variance components ( \pm se) and broad-sense heritability $\left(\mathrm{h}^{2}\right)$ for grain yield of 187 sorghum genotypes analyzed separately within $15-P$ and $14+P$ environments and combined across $P$ treatments

\begin{tabular}{llll}
\hline Term & $-\mathbf{P}$ & Combined & $+\mathbf{P}$ \\
\hline $\boldsymbol{\sigma}_{\mathbf{G}}^{2}$ & $701^{* * *} \pm 90$ & & $1388^{* * *} \pm 183$ \\
$\boldsymbol{\sigma}_{\mathbf{G \times E}}^{2}$ & $423^{* * *} \pm 31$ & & $988^{* * *} \pm 70$ \\
$\mathbf{h}^{2}$ & 0.79 & & 0.76 \\
$\boldsymbol{\sigma}_{\mathbf{G}}^{2}$ & & $983^{* * *} \pm 123$ & \\
$\boldsymbol{\sigma}_{\mathbf{G X E}}^{2}$ & & $503^{* * *} \pm 35$ & \\
$\boldsymbol{\sigma}_{\text {GXP }}^{2}$ & & $47^{* * *} \pm 13$ & \\
$\boldsymbol{\sigma}_{\text {GXEPP }}^{2}$ & & $101^{* * *} \pm 17$ & \\
$\mathbf{h}^{2}$ & & 0.81 & \\
\hline
\end{tabular}

$\mathrm{G}=$ Genotype, $\mathrm{E}=$ Environment (=Location $\times$ Year), $\mathrm{P}=\mathrm{P}$ treatment; ${ }^{* * *}=$ significant at $<0.001$ probability-level.

proportionally smaller genotype-by-environment interactions (GxE) among -P environments. Most of the variation for grain yield in $-\mathrm{P}$ as well as in $+\mathrm{P}$ conditions could be attributed to genotypic effects, with variance component ratios (G:GxE) being greater than one. The genotype-by-P (GxP) interaction variance component estimated across all 29 sites was significant but small. No distinct mega-environments could be delineated in a GGE-biplot analysis (only the 8 common checks were used, see Additional file 2) and the correlation between $-\mathrm{P}$ and $+\mathrm{P}$ grain yield performance (Figure 1$)$ was high $(\mathrm{r}=$ $\left.0.85^{* * *}\right)$, indicating strong correspondence of genotypic performance for grain yield between $-\mathrm{P}$ and $+\mathrm{P}$ conditions . Therefore best linear unbiased predictions (BLUPs) for grain yield across all environments for each genotype could be used for further analyses. Additionally to the grain yield BLUPs across all environments, we also used grain yield BLUPs estimated only across $-\mathrm{P}$ or $+\mathrm{P}$ conditions in order to assess genomic regions associated specifically to grain yield under either $-\mathrm{P}$ or $+\mathrm{P}$ conditions (Table 2). Although genotypes from different sorghum races showed wide variation for grain yield performance in both fertility conditions (Figure 1), the Caudatum accessions showed somewhat more specific adaptation to $+\mathrm{P}$ conditions whereas the Durra and Durra inter-racials accessions were generally better adapted to -P conditions (Figure 1, Additional file 3).

\section{Genetic markers and linkage disequilibrium}

The diversity panel consisted of 187 sorghum genotypes from six West and Central African countries, consisting of eight racial groups ( 3 major- and 5 intermediate-racial groups) (Figure 2, Additional file 1: Table S1, Additional file 4) and included breeding lines and landraces, with differing degrees of photoperiod sensitivity and internode lengths. Most of the genotypes are currently used in breeding programs in the region, but there are no 


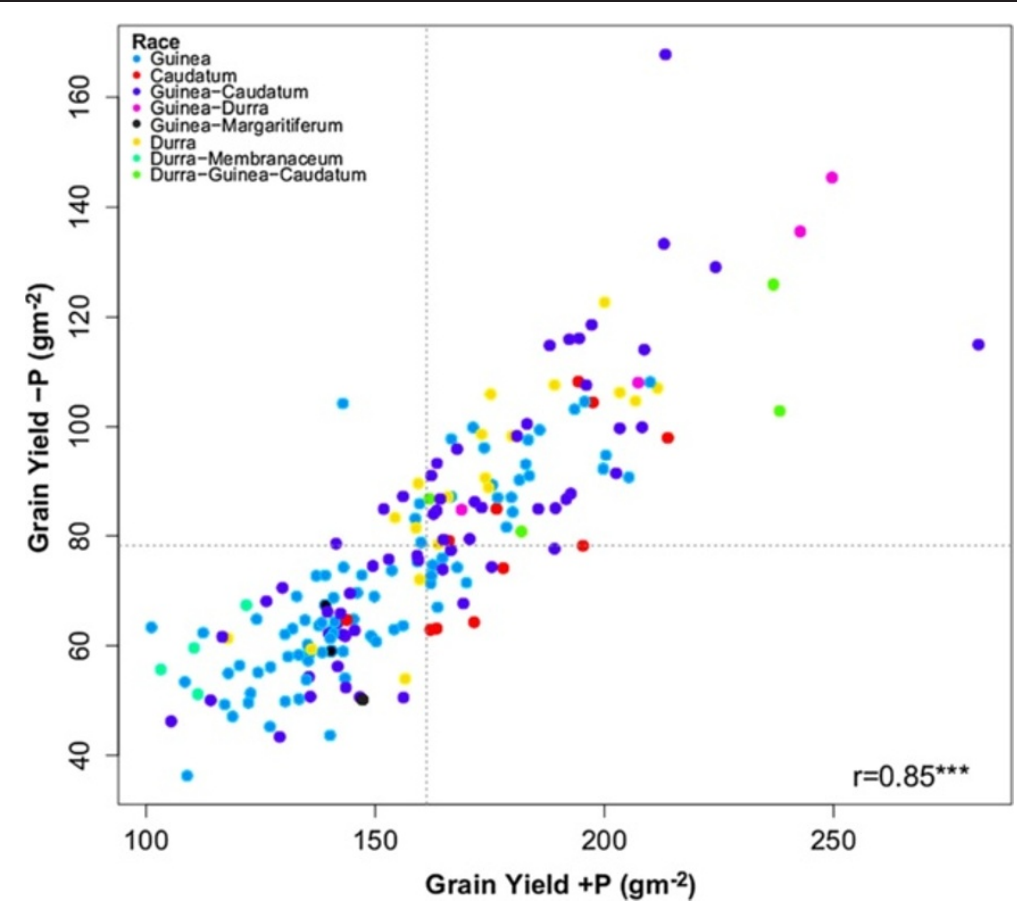

Figure 1 Scatter plot between grain yield performance (BLUPs) of 187 sorghum genotypes estimated across sites in Mali, Niger and Senegal in $15-\mathrm{P}$ environments versus $14+\mathrm{P}$ environments, with genotype dots color-coded for their morphological race-classification.

clear records for ancestry or precise geographic origin of the majority of these genotypes. All genotypes were genotyped using genotyping-by-sequencing (GBS) [20] yielding 220934 SNPs after filtering for $5 \%$ minor allele frequency (MAF) and imputing missing SNPs, giving an average density of one SNP per $3.1 \mathrm{kbp}$. Linkage disequilibrium (LD), calculated for each chromosome separately, decayed rapidly to $50 \%$ of its initial value across all chromosomes within less than $1 \mathrm{~kb}$ (Additional file 5). The high SNP density and the fast LD

Table 2 Association results of four SNP markers within the $A / t_{S B}$ locus with grain yield in $+P,-P$ and $-P /+P$ grain yield ratio across 187 sorghum genotypes

\begin{tabular}{llll}
\hline Condition & Marker & $\mathbf{P}$-value & $\mathbf{R}^{\mathbf{2}}$ \\
\hline $\mathbf{+ P}$ & AltSB_24804 & $1.56 \mathrm{e}^{-05}$ & 0.12 \\
$\mathbf{+ P}$ & AltSB_6083 & 0.62 & 0.01 \\
$\mathbf{+ P}$ & AltSB_8364 & 0.37 & 0.00 \\
$\mathbf{+ P}$ & AltSB_8423 & 0.35 & 0.00 \\
$\mathbf{- P}$ & AltSB_24804 & $1.65 \mathrm{e}^{-07}$ & 0.16 \\
$\mathbf{- P}$ & AltSB_6083 & 0.09 & 0.03 \\
$\mathbf{- P}$ & AltSB_8364 & 0.03 & 0.02 \\
-P & AltSB_8423 & 0.03 & 0.03 \\
$\mathbf{- P / + P}$ & AltSB_24804 & 0.02 & 0.04 \\
-P/+P & AltSB_6083 & $1.77 e^{-04}$ & 0.09 \\
-P/+P & AltSB_8364 & 0.001 & 0.06 \\
-P/+P & AltSB_8423 & 0.001 & 0.06 \\
\hline
\end{tabular}

decay gave a solid basis for genome-wide-association mapping (GWAS).

\section{Relatedness and population structure}

The diversity panel used in this study consisted of five major groups based on kinship and population structure (Figure 2, Additional files 6 and 7). The clustering was primarily associated with differences for morphological race but not for geographic origin. The Guinea and Durra race genotypes formed two very distinct clusters, whereas the Caudatums could be considered intermediate between these two clusters. Generally the inter-racial genotypes were intermediate to their major race clusters, showing different levels of admixture (Additional file 7). A distinct sub-group of Guinea genotypes consisting of the Guinea-margaritiferums clustered closer to the majority of Durra rather than Guinea genotypes, but could only be detected in an admixture analysis using seven, and not the optimum five clusters (Figure 2, Additional file 7).

\section{GWAS for grain yield}

Grain yield BLUPs estimated across 15 -P, $14+$ P, combined across all 29 environments and the grain yield ratios $(-\mathrm{P} /+\mathrm{P})$ were tested for association to 220934 SNPs using a mixed model as described in [21]. Several models were compared and the models correcting for kinship (K) and two to three principal components (PCAs) fitted our data best, had the lowest inflation-factor $(\lambda)$ and therefore the lowest false-discovery rate. 


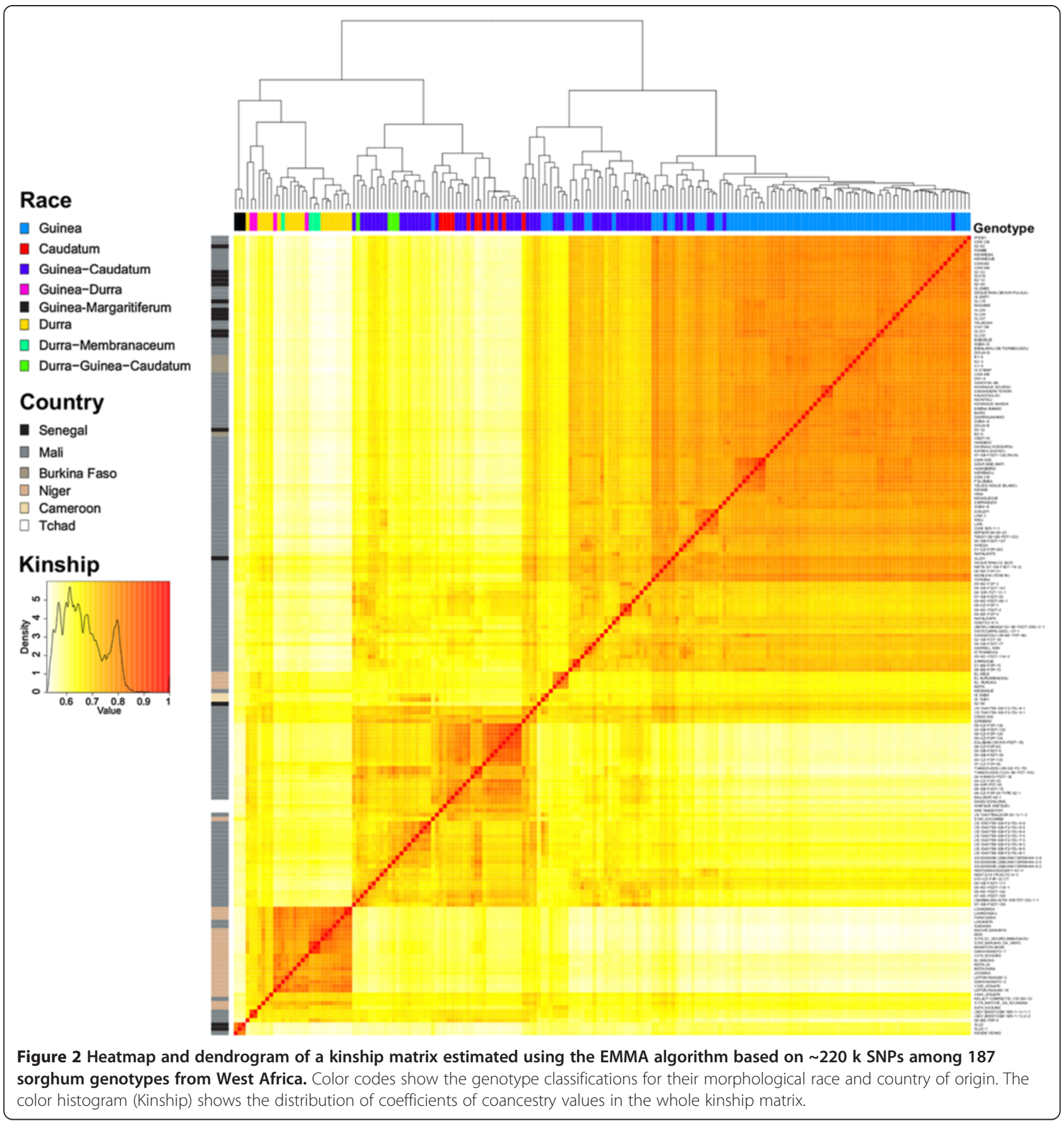

We identified one SNP (S3 71178053) for grain yield across $-\mathrm{P}$ and $+\mathrm{P}$ environments that was significant based on a $p<0.05$ Bonferroni threshold (Figure 3) and explained $15 \%$ of the genotypic variance. The mean yield of accessions harboring the A allele was $44 \mathrm{~g} \mathrm{~m}^{-2}$ $\left(=440 \mathrm{~kg} \mathrm{ha}^{-1}\right)$ higher than that of accessions with the G allele, a difference equivalent to a $37 \%$ yield increase of the A- over the G-allele genotypes (Additional file 8). Three other SNPs with significant association probabilities with grain yield $\left(-\log _{10}(\mathrm{p})>5\right)$ were detected at a physical distance less than $78 \mathrm{~kb}$ and were in tight LD $\left(R^{2}>0.65\right)$ with S3_71178053 (Figure 4). All other GBS derived SNPs within this region had low $-\log _{10}(\mathrm{p})$ values, which was not caused by lower MAF or higher imputation rates (Figure 4) and were not in strong LD with S3_71178053.

Regions on chromosome 6 and 7 also showed strong associations to grain yield (Figure 3). Nine SNPs in gene Sb07g023120 and one SNP (S7_57976035) in gene Sb07g023130 of chromosome 7 were highly associated 


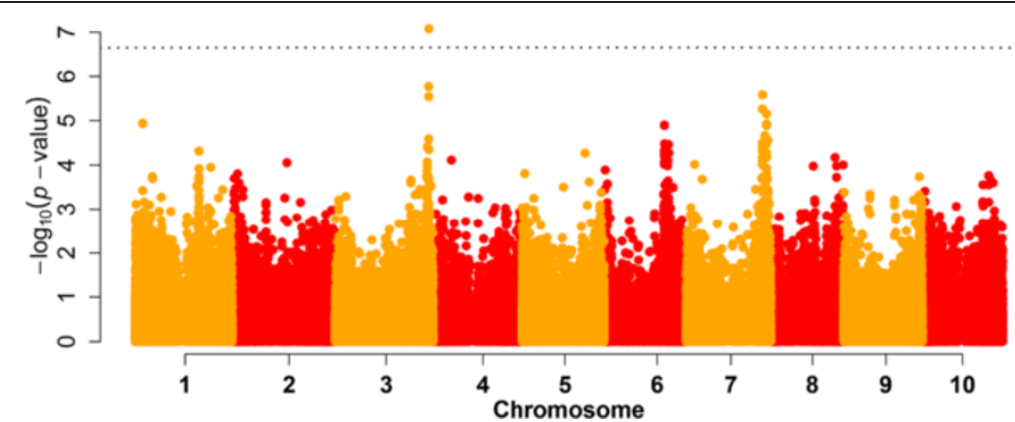

Figure 3 Manhattan plot for sorghum grain yield BLUPs across 29 environments combined over $-\mathrm{P}$ and $+\mathrm{P}$ conditions of 187 genotypes genotyped with $\sim 220 \mathrm{k}$ SNPs with $P$ values shown on a $\log _{10}$ scale and Bonferroni threshold at $p<0.05$ indicated with dashed line.

$\left(-\log _{10}(\mathrm{p})>4.5\right)$. None of the highly associated SNPs on chromosome 6 were located within coding regions. Grain yield BLUPs estimated only within $-\mathrm{P}$ or $+\mathrm{P}$ environments tended to show similar associations, but these single P-level associations had less power in detecting significant SNPs (Additional file 9). S3_71178053 was the most significant SNP for grain yield under both $-\mathrm{P}$ and $+\mathrm{P}$ conditions, whereas we observed differences across the other chromosomes depending on the P-level. SNPs on chromosome 6 played a more important role under -P conditions, whereas chromosome 10 exhibited a region highly associated to grain yield under $+\mathrm{P}$ conditions (Additional file 9). Examination of $-\mathrm{P} /+\mathrm{P}$ grain yield ratios as an indicator for specific adaptation to $-\mathrm{P}$ conditions revealed one single SNP on chromosome 5, although not located in a coding region, and a second SNP on chromosome 1, S1_54947742 $\left(-\log _{10}(\mathrm{p})>4.5\right)$, which caused a missense variant in gene Sb01g032090, leading to an amino acid change from methionine to isoleucine (Additional file 10: Table S2).

\section{Candidate gene association}

Twelve coding regions, five with putative gene functions and seven uncharacterized proteins, occur within the $78 \mathrm{~kb}$ spanning region on chromosome 3 between the SNPs S3_71101374 and S3_71178053 (Figure 4). Only five out of 62 SNPs within this region were located within coding regions and only two out of these five SNPs were highly associated to grain yield performance. The Al-tolerance gene SbMATE (Sb03g043890) is also located in the same region. As no SNPs from the GBS dataset were located in $S b M A T E$, we used $A l t_{S B}$ specific SNPs within SbMATE and in close vicinity to SbMATE [22] to test for association to grain yield under $-\mathrm{P}$ and + $\mathrm{P}$ conditions and to the $-\mathrm{P} /+\mathrm{P}$ grain yield ratio. Four of the nine $A l t_{S B}$ specific SNPs showed promising associations; three of which showed $-\mathrm{P}$ specific associations and the fourth, AltSB_24804, had the strongest association to grain yield under $-\mathrm{P}$ as well as $+\mathrm{P}$ conditions (Table 2, Figure 5). AltSB_24804 showed the highest minor allele frequency and explained 12 and $16 \%$ of the genotypic variance for grain yield under $+\mathrm{P}$ and $-\mathrm{P}$ conditions, respectively, resulting in a $37 \mathrm{~g} \mathrm{~m}^{-2}$ and $25 \mathrm{~g} \mathrm{~m}^{-2}$ grain yield increase, respectively. However, this SNP explained only $4 \%$ of the genotypic variance for $-\mathrm{P} /+\mathrm{P}$ grain yield ratio, indicating no $-\mathrm{P}$ specificity. The other three SNPs located within or in close proximity to SbMATE explained 6-9\% of the genotypic variance for grain yield ratio, significantly increased mean grain yield ratio from 0.47 to 0.54 and increased $-\mathrm{P}$ grain yield from 77 to $86 \mathrm{~g} \mathrm{~m}^{-2}$. AltSB_24804 was in strong LD $\left(\mathrm{r}^{2}>0.7\right)$ with the four SNPs $\left(-\log _{10}(\mathrm{p})>5\right)$ on chromosome 3, whereas the other Alt $_{S B}$ specific SNPs showed no LD based on squared correlation of allele frequencies $\left(r^{2}<0.02\right)$. However, this might be due to unmatched allele frequencies, since $\mathrm{D}^{\prime}$ values $\left(\mathrm{D}^{\prime}>0.7\right)$ indicated strong LD.

\section{Discussion}

\section{Field experiments}

The large grain yield and plant height reductions and the delay in flowering in the $-\mathrm{P}$ compared to the $+\mathrm{P}$ conditions indicate important growth differences between the two $\mathrm{P}$ treatments, that should permit a genetic study of adaptation to P-limited conditions [5]. Although the $-\mathrm{P}$ trials always had significantly lower grain yields than the $+\mathrm{P}$ trials, some $\mathrm{P}$ limitations in $+\mathrm{P}$ trials cannot be discounted, especially for three $+\mathrm{P}$ trials due to the high P-retention in these low $\mathrm{pH}$ soils and late application of $\mathrm{P}$ fertilizer, thus reducing the impact of $\mathrm{P}$ fertilizer application on plant development and final grain yield [23]. Despite an average $52 \%$ grain yield reduction in $-\mathrm{P}$ relative to $+\mathrm{P}$ conditions, the sorghum genotypes exhibited a strong correspondence between $\mathrm{P}$ and $+\mathrm{P}$ grain yield performance $\left(\mathrm{r}=0.85^{* * * *)}\right)$. This suggests that WA sorghums have a general good adaptation to P-limited conditions and corresponds with previously reported higher $\mathrm{P}$ uptake and use efficiency of sorghum compared to other crops [5,24-29]. The strong correlation between $-\mathrm{P}$ and $+\mathrm{P}$ conditions and the small GxP 


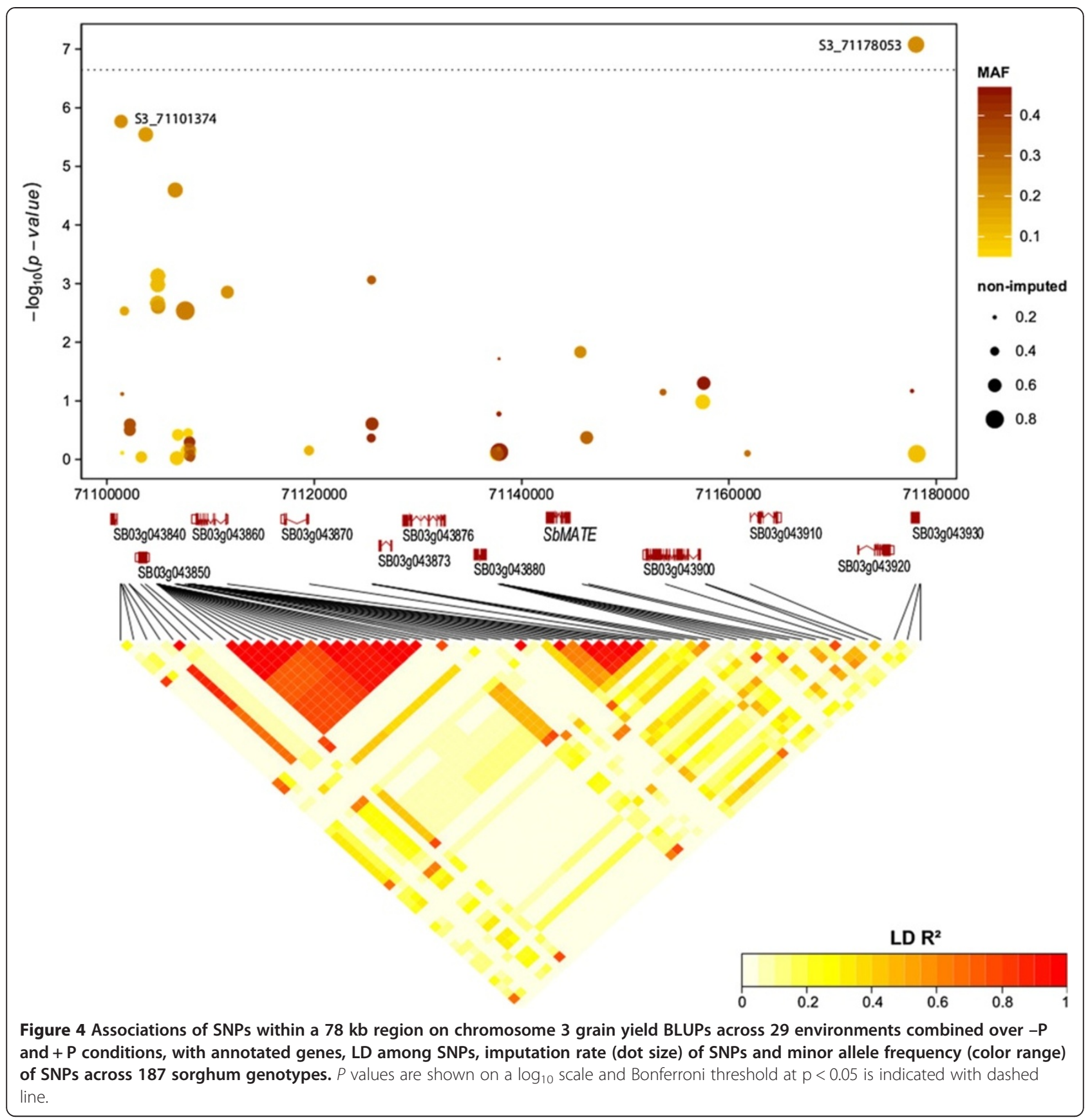

variance component suggest that selection under $+\mathrm{P}$ conditions could result in gains under $-\mathrm{P}$ conditions. Nevertheless, the slightly higher broad sense heritability in -P (Table 1) and the specific adaptation of some genotypes towards $-\mathrm{P}$ conditions (Figure 1, Additional file 3) suggests that direct selection in $-\mathrm{P}$ conditions is more efficient for targeting P-limited production systems, as was shown by [5].

The phenological and racial diversity of our panel was so wide that the entire set would not normally be cultivated in the same environments. The Durra-race genotypes and very early maturing Caudatum-race genotypes are cultivated in the Sahelian zone whereas the Guinea-race genotypes are grown in the Sudanian zone of WA [30,31]. Our field trials were therefore designed to evaluate accessions in their respective zone of adaptation. The relatively small GxE-interaction and lack of clear mega-environment delineations based on zones (Additional file 1: Table S1, Additional file 2) may be due, in part, to the experimental design in which only eight Guinea, Caudatum and GuineaCaudatum genotypes with acceptable adaptation to both zones were common across all environments, hence only 


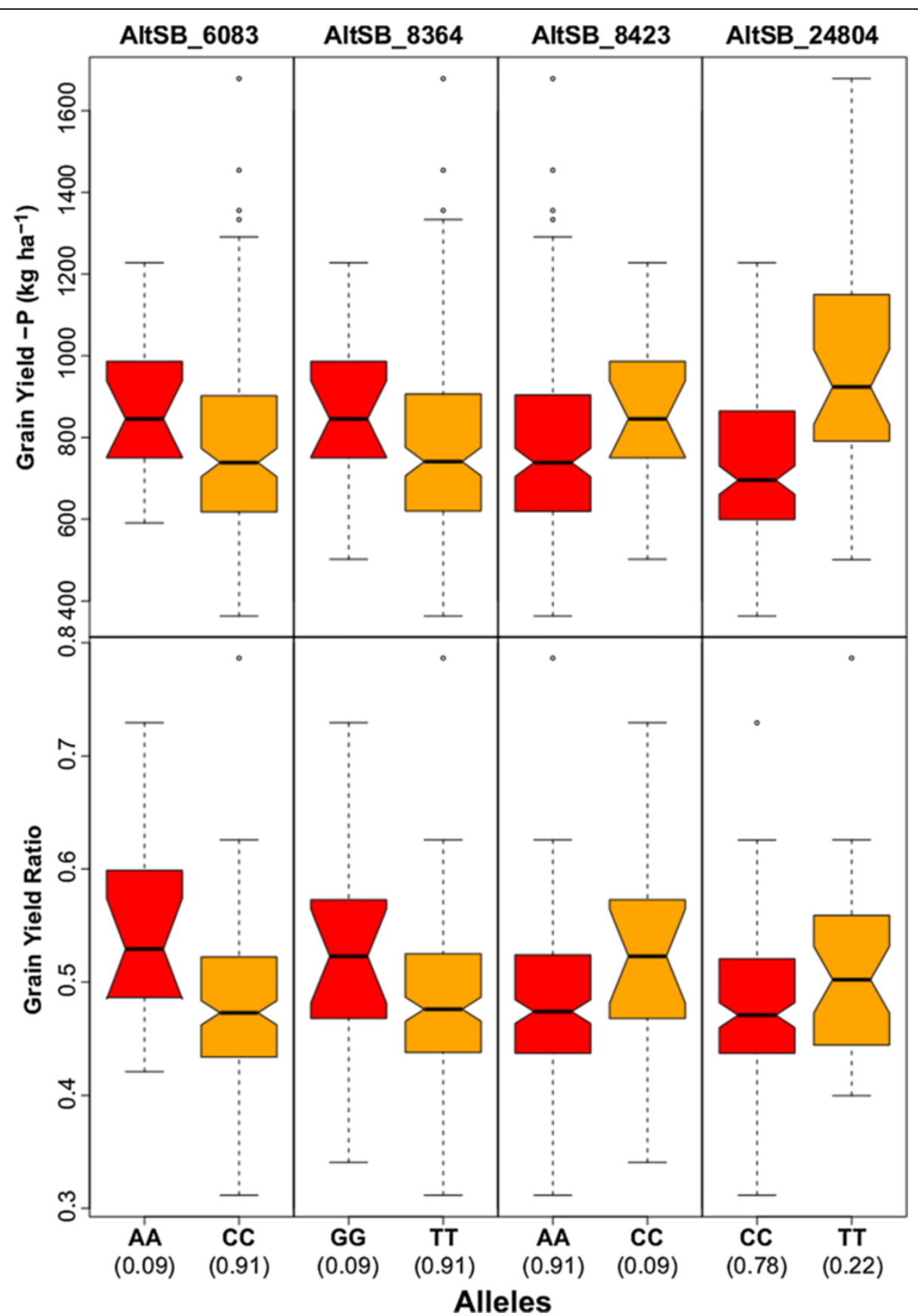

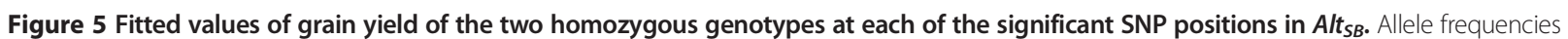
are given between brackets.

these common genotypes actually displayed the GxEinteraction pattern.

\section{Genetic diversity}

Genetic diversity among the 187 WA sorghum genotypes was high, with considerable separation of the three races, but no separation due to geographic origin. Studies showing clear geographic differentiation are mostly based on worldwide collections [32-34], whereas studies considering germplasm from within a smaller region find mostly racial differences [35]. A group of Guineamargaritiferum accessions was clearly separated from the other races, but clustering closer to the Durra- rather than other Guinea-race accessions, confirming the genetic distinctness of this Guinea-sub-race [32,34,36]. Although there were clear racial differentiations, we also observed a high level of genetic admixture (Additional file 7 ) in our diversity panel, suggesting that considerable 
gene flow has occurred in the WA region and thus providing a high genetic diversity exploitable in GWAS. Furthermore, the rapid LD decay, in agreement with recent studies based on GBS [34] and re-sequencing data [36] of diverse sorghum genotypes additionally points to the high genetic diversity of our panel and its usefulness for GWAS with a mapping resolution on gene-level.

The -P specific adaptation and general good performance of the Durra genotypes (Figure 1, Additional file 3) makes this germplasm group particularly promising for use in future sorghum breeding efforts. Their genetic distinctness from the Guinea pool suggest, that Durra by Guinea-race crossing could be explored to achieve high heterosis and to obtain broader adaptation [37] if acceptable grain and glume types can be obtained from these inter-racial matings.

\section{Genomic regions for grain yield under P-limited conditions}

This study, the first to our knowledge, identifies regions in the sorghum genome related to grain yield under P-limited soils and a genomic region with a possible pleiotropic effect for Al-tolerance and grain yield productivity under P-limited conditions. Recent work show that over-expression of citrate synthesis and malate transporter genes improve Al-tolerance and $\mathrm{P}$ uptake under low $\mathrm{P}$ conditions in several species [13-15], supporting the hypothesis that Al-tolerance and $\mathrm{P}$ uptake under low $\mathrm{P}$ conditions can be regulated by similar processes [6]. However citrate release is predominantly induced by $\mathrm{Al}$ and to a much lesser extent by low $\mathrm{P}$ conditions [16-19]. Al-saturation values between $10-28 \%$ were found in six out of 16 field trials analyzed for Alsaturation (Additional file 11: Table S3), values which are at or near the threshold for limiting sorghum root growth due to Al-toxicity. Thus, although the Alstress may have been mild, these conditions could have induced SbMATE expression that increased citrate release and benefitted $\mathrm{P}$ availability and retention of viable roots [12], thus leading to an increased $\mathrm{P}$ uptake. Furthermore, Al saturation shows generally a high spatial variation [38] and has been reported to have a major influence on crop growth in WA [39], therefore an impact of $\mathrm{Al}$ toxicity on crop growth in the other environments cannot be ruled out. This might have also lead to the observed strong association of grain yield from both P-treatments to the same genomic region.

The strong effect of SbMATE specific SNPs and their rather tight linkage to the other significant SNPs within the $78 \mathrm{~kb}$ region identified by GWAS suggests that grain yield under P-limited conditions is possibly controlled by SbMATE and likely other genes in this region. S3 71178053, the SNP with the strongest association to grain yield caused a missense mutation in gene Sb03g043930, leading to an amino-acid change from threonine to alanine (Additional file 10: Table S2). Since Sb03g043930 is an uncharacterized protein, it is not clear how it might be involved in grain yield production or SbMATE regulation. Recent evidence shows that the SbMATE expression in sorghum is regulated by additional factors [40] and thus its expression is more complex than previously thought. The linked SNPs identified in our study could be valuable for studying these background factors. The C2H2-type zinc-finger transcription factors (STOP 1 and 2) regulate MATE expression in A. thaliana $[41,42]$, and orthologous genes to STOP1 have been found in several other crops [43]. Other C2H2-type zinc finger genes are also known to play a role in $\mathrm{P}$ adaptation and are mostly locally regulated (e.g. roots), whereas C3HC4-type zinc-finger genes are systematically regulated [44] and act as transcription factors in early low $P$ adaptation [45] and other abiotic stress adaptation [46]. SNP S3_71101374, which was highly associated to grain yield performance (Figure 4) and in strong linkage to AltSB_24804, is located close to Sb03g043850, which is predicted to be a C3HC4-type zinc-finger gene (Additional file 10: Table S2), hence possibly involved in adaptation to P-limited conditions. The highly associated AltSB specific SNP AltSB_24804, located in the 3' region of SbMATE, was shown to be associated to Al-tolerance in another study, although showing rather small effects [22]. The other three SNPs within or closer to SbMATE, especially AltSB_6083, which showed specific responses to $-\mathrm{P}$ conditions, are known to be highly responsible for Al-tolerance in sorghum [22], pointing to a possible pleiotropic regulation of $\mathrm{Al}$ tolerance and specific - $\mathrm{P}$ adaptation. However, we did not evaluate this set of genotypes specifically for Altolerance in soil-based or hydroponic systems, but previous studies showed a very strong effect of AltSB_6083 on phenotypic Al-tolerance, that support this hypothesis. Although the frequency of these positive $-\mathrm{P}$ specific SNPs was low (9\%) in our WA panel, the frequency appears to be much higher in the Guinea-race germplasm, with $95 \%$ of the genotypes carrying the positive SbMATE alleles being either pure Guinea race or Guinea introgressed genotypes. The low MAF and confounding of population structure might have limited a stronger association of these SNPs to low P grain yield [22]. A similar allele frequency $(0.1)$ of these SNPs and a higher frequency in WA Guinea sorghums was also found in a worldwide sorghum collection [47], hence pointing to this germplasm group as an important source for Altolerance in sorghum [22].

The rather high association on chromosome 7 to grain yield under both $-\mathrm{P}$ and $+\mathrm{P}$ conditions may have been 
caused by an unidentified foliar disease resistance gene. The SNP with the best association to grain yield was located within an uncharacterized protein Sb07g023120 but was also in strong $\operatorname{LD}\left(\mathrm{R}^{2}>0.85\right)$ with SNPs in Sb07g023130. Sb07g023130 is similar to NADPH HC toxin reductase, which confers specific resistance reaction to Helminthosporium (Cochliobolus carbonum) in maize [48]. Although Cochliobolus carbonum is not known as a major sorghum disease in WA, it is known to cause foliar diseases in sorghum [49] and the HC toxin reductase mechanism is also conserved in other grasses and acts as resistance response to Cochliobolus carbonum [50]. Although foliar disease scoring was not done in our study to enable further investigation, the effect on chromosome 7 being expressed under both $+\mathrm{P}$ and $-\mathrm{P}$ conditions would be consistent with some type of biotic resistance.

Specific adaptation to P-limited conditions was assessed by the $-\mathrm{P}$ versus $+\mathrm{P}$ ratio of grain yield performance. Although no genomic region was found with strong associations to $-\mathrm{P} /+\mathrm{P}$ grain yield ratio, $\mathrm{SNPs}$ with $-\log _{10}(\mathrm{p})>4.3$ may indicate the existence of mechanisms involved in specific -P adaptation other than SbMATE. One of these, SNP S5_2179409 on chromosome 5 was located in an intron region of gene Sb05g001996. Sb05g001996 is predicted to be of the rhamnogalacturonan lyase family, hence possibly involved in cell wall degradation by disrupting rhamnogalacturonan [51]. This might imply that Sb05g001996 is involved in specific low P adaptation by cell wall degradation and consequently in $\mathrm{P}$ translocation at later developmental stages. Somewhat similarly, S1_54947742 causes a missense variant in Sb01g032090, which is predicted to be a papain family cysteine protease. Papain family cysteine proteases are known to be involved in programmed cell death, either due to senescence and therefore nutrient cycling or as pathogen defense [52,53]. Phosphorous translocation from shoot to grain is known to be of major importance in sorghum, and $\mathrm{P}$ harvest index is increased under P-limited conditions [24]. The existence of significant genotypic differences for specific -P grain yield, measured as $-\mathrm{P} /+\mathrm{P}$ grain yield ratio (unpublished data), but no identification of a genomic region with clear effects for this specific $-\mathrm{P} /+\mathrm{P}$ grain yield ratio may result from the existence of multiple adaptive mechanisms contributing to this complex trait.

\section{Implications for applied breeding}

Our test sites represent a wide range of soils and climate conditions relevant to sorghum production in WA. It is thus remarkable that we found individual SNPs accounting for up to $16 \%$ of the genotypic variation for grain yield. The significant GxP interaction, higher response to direct selection under $-\mathrm{P}$ conditions [5] and the low frequency of Al-tolerance in WA sorghum, indicate the need for selection efforts specifically targeting P-limited and high $\mathrm{Al}$-saturation production environments, which are of major importance for WA sorghum producers. Our results suggesting that the same genomic region or even the same gene, SbMATE, possibly contribute to adaptation to both conditions focuses attention on this region. Currently we are evaluating further diversity and bi-parental mapping sets for performance under low $\mathrm{P}$ conditions to validate these findings. Once validated, it should be possible to incorporate the desired loci for both traits into elite breeding material with minimum linkage drag using marker assisted selection. Furthermore, the gene specific markers within $A l t_{S B}$ will make allele mining possible in large germplasm collections, hence increase allelic frequency and Al-tolerance of the currently used germplasm. These markers are already available on the Integrated Breeding Platform of the Generation Challenge Program [https://www.integratedbreeding.net/]. All other markers, once validated, will be also accessible on this platform to help sorghum breeders select promising genotypes for two traits in one sweep.

\section{Conclusions}

We provide the first evidence for a genetic and possible molecular link between Al-tolerance, P-efficiency and grain yield potential, opening possibilities for the use of molecular breeding tools to facilitate development of cultivars with superior performance under the predominant poor soil conditions of WA. The significant GxP interaction, higher response to direct selection under -P conditions and the low frequency of Al-tolerance in WA sorghum, indicate the need for selection efforts specifically targeting P-limited and high Al-saturation production environments. Our results point to the possibility that adaptation to both conditions is pleiotropically controlled by the same genomic region or even the same gene, SbMATE. The identified SNPs can help accelerate breeding for increased sorghum productivity under the two most important abiotic constraints to sorghum productivity in WA, Al toxicity and $\mathrm{P}$ deficiency, and contribute to assuring food security in WA.

\section{Methods}

\section{Field trials}

A total of 187 sorghum genotypes from six West and Central African countries, consisting of researcher-bred and landrace varieties representing eight racial groups (Guinea, Durra, Caudatum and 5 intermediate groups; Additional file 4) and differing degrees of photoperiod sensitivity and stem internode lengths, were grown in paired -P (0 kg P ha ${ }^{-1}$ application) and $+\mathrm{P}(20-40 \mathrm{~kg} \mathrm{P}$ $\mathrm{ha}^{-1}$ application, Additional file 11: Table S3) experiments in each location-year combination. A total of 29 rain fed field experiments (Additional file 1: Table S1), 
consisting of $15-\mathrm{P}$ and $14+\mathrm{P}$ environments, were successfully conducted in three countries (Mali, Niger, Senegal; Additional file 12) at five locations over seven years (2006-2012). Due to field size constraints (max. 320 plots per experiment) and specific adaptation requirements for the Sahelian and Sudanian zones, three separate series of trials were conducted with subsets of the 187 genotypes (Additional file 1: Table S1). At least eight common genotypes considered to have acceptable adaptation to both the Sudanian and Sahelian zones were included in all experiments to enable a combined analysis across all sites, hence fit BLUPs for each genotype across all environments and estimate genotype-byenvironment interaction. The set 1 genotypes, consisting of 36 landrace and 34 research-bred varieties originating from the Sudanian zone, were tested at two locations in the Sudanian zone of Mali from 2006-2010 in the first series of trials comprising eight $-\mathrm{P}$ and seven $+\mathrm{P}$ environments [5]. Set 2 genotypes, consisting of 54 landraces from the Sahelian zone and 28 early maturing researchbred varieties, were evaluated at four Sahelian zone locations in Mali, Niger and Senegal from 2010-2012 in the second series of trials, resulting in five pairs of $-\mathrm{P}$ and + $\mathrm{P}$ environments. Set 3 genotypes, consisting of Sudanian zone adapated genotypes (56 researcher bred and 4 landrace varieties), was grown at a single Sudanian zone location in Mali in 2011 and 2012, providing two pairs of $\mathrm{P}$ and $+\mathrm{P}$ environments. Four late maturing genotypes in set 1 were dropped from the analyses due to severe grain losses due to sorghum midge (Stenodiplosis sorghicola) infestation. A number of the trials conducted were not used in this analysis due to crop failure, heterogeneous growth due to edaphic constraints other than low P, such as soil crusting and variable depth of soil hard-pan and planting errors.

All experiments were laid out in an $\alpha$-design with four replicates. Plots consisted of two three-meter rows with 75-80 cm distance between rows and 30-40 cm between hills within rows. Hills were thinned to two plants, resulting in a total of 6-9 plants $\mathrm{m}^{-2}$. A single border row planted with a common genotype of medium height and maturity separated each test plot to minimize neighbor effects. Soil samples were taken from most field experiments and analyzed for plant available soil $\mathrm{P}$ (Bray-1P) [54], pH- $\mathrm{H}_{2} \mathrm{O}$ and subset of samples were tested for aluminum saturation (\% $\mathrm{Al}$ of $\mathrm{CEC}$ ) (Additional file 11: Table S3). The $-\mathrm{P}$ fields had an average Bray-1P value of $6.3 \mathrm{mg} \mathrm{P} \mathrm{kg}^{-1}$ soil, whereas the $+\mathrm{P}$ fields averaged $16.5 \mathrm{mg} \mathrm{P} \mathrm{kg}^{-1}$ soil. The $-\mathrm{P}$ and $+\mathrm{P}$ sites had similar $\mathrm{pH}$ values, which averaged 5.6.

\section{Phenotypic statistical analysis}

Each single environment was separately analyzed for grain yield using a mixed model with genotypes as fixed and replications and incomplete blocks nested within replications as random. When this model had repeatability values below 0.75 , several spatial models were fitted (see [55]) and the optimum model was selected based on its AIC value. Predicted values and standard errors were computed for each genotype in each environment and were used in a combined weighted two-stage analysis [5] with genotypes and environments as random within one fertility level, yielding best linear unbiased predictors (BLUPs) for each genotype. Genotypic variances differed within individual environments (Additional file 1: Table S1) and correlations among the various environments likewise differed (Additional file 2). Several variance and co-variance models (unstructured, diagonal, factorial) were fitted to model specific variance co-variance structures but they did not converge (e.g. unstructured model) or did not improve the model fit based on AIC estimates (e.g. diagonal, factorial). Therefore instead of these models a compound symmetry model was used for our analyses. For a higher computational efficiency, the variance components were first estimated using the AI algorithm within Genstat 15 and then used as starting values running the same model but using the Fisherscoring option to estimate broad-sense heritability based on [56]. Further, a combined analysis across P-treatments was conducted with P-treatment as fixed and genotypes and environments (location $\mathrm{x}$ year-combination) as random to estimate the genotype-by-P interaction. Similar as in the analysis within each fertility level, we fitted several variance co-variance models. Convergence problems and lack of superiority of model fit based on AIC, lead us to a compound symmetry model.

Grain yield ratios $(-\mathrm{P} /+\mathrm{P})$ were estimated, whereby grain yield BLUPs of the $-\mathrm{P}$ trials were divided by the grain yield BLUPs of the $+\mathrm{P}$ trials. Genotypes showing a higher grain yield ratio are expected to be specifically adapted to $-\mathrm{P}$ conditions.

For possible mega-environment delineation and $\mathrm{GxE}$ visualization a genotype-genotype-by-environment (GGE) analysis was conducted for grain yield across all $-\mathrm{P}$ and + $\mathrm{P}$ sites using only grain yield data from the 8 common genotypes [57]. All data analyses were done with the Genstat 15 software.

\section{Genomic data}

Total genomic DNA was extracted from a single 20 day old plant of each line by using DNeasy Plant Mini Kit (QIAGEN). Extracted DNA was checked for quality and quantity by Nanodrop and gel analyses. GBS libraries were prepared and analyzed at the Institute for Genomic Diversity (IGD), according to [20], using the enzyme ApeKI for digestion and creating a library with 188 unique barcodes. GBS libraries were sequenced on the Illumina HiSeq2000. The GBS analysis pipeline Version 3.0.121, an extension to the Java program TASSEL [58], 
was used to call SNPs from the sequenced GBS library. The sequenced tags were aligned to the sorghum reference genome BTx623 v1.0 [59] and only tags with at least $10 x$ coverage were retained. Ambiguous or heterozygous sites were set as missing SNPs and finally imputed with all other missing SNPs using NPUTE [60] for each chromosome separately. Imputation accuracy was on average above $96 \%$. In total 308623 SNPs were retrieved. After filtering for 5\% minor allele frequency (MAF) using TASSEL, 220934 SNPs were retained and used for further analysis. Gene specific markers for the Alt $_{S B}$ locus were created by EMBRAPA and converted to the KASPar system at LGC-Genomics [22]. All genotypes were analyzed for these markers.

\section{Population genetics}

Pairwise linkage disequilibrium (LD) was calculated for each chromosome separately in TASSEL using a sliding window size of 50 SNPs. Average LD decay across each chromosome was calculated and plotted in R. LD within a specific genomic region was calculated and visualized using LDheatmap in $\mathrm{R}$ [61]. Population structure was estimated using principal component analysis (PCA) as implemented in SNPrelate [62] and Admixture [63]. Kinship (K) among genotypes was calculated using the EMMA algorithm within GAPIT [64]. Allele frequencies of each site were calculated in TASSEL.

\section{Association mapping}

The grain yield BLUPs estimated across $-\mathrm{P},+\mathrm{P}$, combined across all $-\mathrm{P}$ and $+\mathrm{P}$ sites and the grain yield ratios $(-\mathrm{P} /+\mathrm{P})$ were used in a genome wide association study (GWAS). GWAS was carried out in R using the package GenABEL [21] running several models using the polygenic function correcting only for kinship or for kinship and population structure using either one, two, three, five or ten PCAs. The best model was chosen based on the lambda estimate of the quantile-quantile plots of the expected versus the observed p-values, thus having the lowest genome-wide inflation. For most traits a model with one to three PCAs fitted best. Multiple testing was corrected using a Bonferroni threshold of $\mathrm{p}<0.05$ (p-value/SNPs). Association mapping for the $A t_{S B}$ specific markers was performed in TASSEL using a compressed mixed linear model correcting for kinship and three PCAs [65]. Possible causal changes of associated SNPs were tested by the Variant effect Predictor of the www.gramene. org website using the sorghum genome v.1.0.

\section{Additional files}

Additional file 1: Table S1. Single environment analysis results: the different genotype sets (GenoSet), number of genotypes tested within each set (\#Geno), environmental zone in which the experiments were conducted (Zone), name of the environment as site-year combination (Site-Year), phosphorus treatment (P-level), grand mean for grain yield (Mean), genetic variance component $\left(\sigma^{2} \mathrm{G}\right)$, genetic coefficient of variation $(G C V)$, residual variance component $\left(\sigma_{\text {error }}^{2}\right.$ ), standardized variance of a difference across all genotype pairs (stdzaVD) and repeatability estimate $\left(w^{2}\right)$

Additional file 2: GGE-Biplot of sorghum grain yield of eight genotypes evaluated across 29 environments (15 -P and $14+P$ environments). The environments are coded as: first three letters indicate the location, followed by the year and the P-treatment ( $L P=-P, H P=+P)$.

Additional file 3: Boxplots of $-\mathrm{P} /+\mathrm{P}$ grain yield ratios of the seven main racial groups existing among the 187 sorghum genotypes from West Africa.

Additional file 4: Genotype classification including information on: the different genotype sets (GenoSet), the eight common genotypes (ComGeno), the genotype ID (Taxa), the variety name (Variety), the racial classification based on morphological characters (Race), the country of origin (Country) and the alleles of some of the most important SNPs identified in this study.

Additional file 5: Average linkage disequilibrium (LD) decay of each chromosome based on $\mathbf{r}^{2}$ estimates. LD estimates were based on $\sim 220 \mathrm{k}$ SNPs derived from genotyping-by-sequencing and 187 West African sorghum genotypes.

Additional file 6: Population structure based on principal components 1 and 2 of the 187 sorghum genotypes with their corresponding morphological race classification.

Additional file 7: Hierarchical population structuring using Admixture assuming $K=\mathbf{3}, \mathbf{5}$ and $\mathbf{7}$. $K=5$ was best model based on error of cross-validations. The 187 sorghum genotypes are shown with their variety name and their corresponding morphological race classification.

Additional file 8: Fitted values (BLUPs) of the genotype groups carrying the most significant SNPs on $\mathrm{Chr} 3$ and $\mathrm{Chr7}$ for grain yield across $-\mathrm{P}$ and $+\mathrm{P}$ conditions combined and on Chr 1 and Chr5 for grain yield ratio.

Additional file 9: Manhattan plots of grain yield in $-P(A)$, grain yield in $+P(B)$ and grain yield ratio $-P /+P(C)$. $P$ values are shown on a $\log _{10}$ scale.

Additional file 10: Table S2. Results of most significant SNPs for grain yield in $-P(G Y-P),+P(G Y+P)$, across both P-treatments (GY_ALL) and for grain yield ratios (-P/+P) (Ratio). Shown are: SNP ID, its position (Pos) on chromosome $(\mathrm{Chr})$ of the sorghum reference genome $\mathrm{v} 1.4$ and the reference and alternative allele at this SNP (Allele), its p-value in GWAS, the explained genotypic variance $\left(R^{2} \%\right)$, the consequence (CQs), the amino acid change (AA), the codon change (Codon), the distance in base pairs to another gene in close vicinity $(<50 \mathrm{~kb})$, the ID of this gene (Gene) and its predicted function based on different databases as summarized on www.phytozome.com.

Additional file 11: Table S3. Single environment characteristics: sowing date, total amount of rain in whole year ( $\mathrm{mm}$ ), amount of $\mathrm{N}$ and $\mathrm{P}$ applied as fertilizer ( $\mathrm{kg} / \mathrm{ha}), \mathrm{pH}$ of the soil measured in water $(\mathrm{pH})$, soil content of plant available P measured as Bray-1P (mg P/kg soil), total amount of $P$ in the soil ( $\mathrm{mg} P / \mathrm{kg}$ ), aluminum saturation of the soil as percent of cat ion exchange capacity (CEC) $\left(\mathrm{Al}^{3+}\right.$-sat.), timing of soil sampling (SS) and the amount and type of extra fertilizer added per hectar.

Additional file 12: Map of field trial locations with isohytes. Locations circled and highlighted are Sahelian sites, while others are located in the Sudanian zone of West Africa.

\section{Competing interests}

The authors declare that they have no competing interests.

\section{Authors' contributions}

Designed and conducted the field experiments: HFWR, BIGH, EW, WLL, NC, MA, AD, AOT. Analyzed the data: WLL. Wrote manuscript: WLL, HFWR, BIGH, JVM. All authors read and approved the final manuscript. 


\section{Acknowledgements}

The vital support of the technical staff of the Institut de Economie Rural, Mali, the Institut Sénégalais de Recherches Agricoles, Senegal, the Institut National de la Recherche Agronomique du Niger, Niger, and the International Crops Research Institute for the Semi-Arid Tropics, Mali, for conducting the yield trials is greatly appreciated. We thank Sharon E. Mitchell at the Institute for Genomic Diversity at Cornell University for the production and provision of the GBS marker data. The financial support of the McKnight Foundation Collaborative Crop Research Program, the Generation Challenge Program and the German Federal Ministry for Economic Cooperation and Development (BMZ) is gratefully acknowledged. The work was undertaken as a part of the CGIAR Dryland Cereals Research Program.

\section{Author details}

'Institute of Plant Breeding, Seed Science and Population Genetics, University of Hohenheim, Fruwirthstr. 21, 70599 Stuttgart, Germany. ${ }^{2}$ International Crops Research Institute for the Semi-Arid Tropics, P 320, Bamako, Mali. ${ }^{3}$ Institut Sénégalais de Recherches Agricoles, BP 3320, Thiès, Senegal. Institut National de la Recherche Agronomique, CERRA de Maradi, BP 240, Maradi, Niger. ${ }^{5}$ 'Institut d'Economie Rurale, BP 258, Bamako, Mali. ${ }^{6}$ Embrapa Maize and Sorghum, Rod. MG 424, Km 65, 35701-970 Sete Lagoas, Minas Gerais, Brazil.

Received: 20 February 2014 Accepted: 22 July 2014

Published: 12 August 2014

\section{References}

1. Vom Brocke K, Trouche G, Weltzien E, Barro-Kondombo CP, Gozé E, Chantereau J: Participatory variety development for sorghum in Burkina Faso: farmers' selection and farmers' criteria. Field Crops Res 2010, 119:183-194.

2. Buerkert A, Bationo A, Piepho H-P: Efficient phosphorus application strategies for increased crop production in sub-Saharan West Africa. Field Crops Res 2001, 72:1-15.

3. Kochian LV, Hoekenga OA, Pineros MA: How do crop plants tolerate acid soils? Mechanism of aluminum tolerance and phosphorus efficiency. Annu Rev Plant Biol 2004, 55:459-493.

4. Kochian LV: Plant nutrition: rooting for more phosphorus. Nature 2012 488:466-467.

5. Leiser WL, Rattunde HFW, Piepho H-P, Weltzien E, Diallo A, Melchinger AE, Parzies HK, Haussmann BIG: Selection strategy for sorghum targeting phosphorus-limited environments in West Africa: analysis of multi-environment experiments. Crop Sci 2012, 52:2517-2527.

6. Magalhaes JV, Liu J, Guimarães CT, Lana UGP, Alves VMC, Wang Y-H, Schaffert RE, Hoekenga OA, Piñeros MA, Shaff JE, Klein PE, Carneiro NP, Coelho CM, Trick HN, Kochian LV: A gene in the multidrug and toxic compound extrusion (MATE) family confers aluminum tolerance in sorghum. Nat Genet 2007, 39:1156-1161.

7. Kochian LV: Cellular mechanisms of aluminum toxicity and resistance in plants. Annu Rev Plant Biol 1995, 46:237-260

8. Zhang FS, Ma J, Cao YP: Phosphorus deficiency enhances root exudation of low-molecular weight organic acids and utilization of sparingly soluble inorganic phosphates by radish (Raghanus satiuvs L.) and rape (Brassica napus L.) plants. Plant Soil 1997, 196:261-264.

9. Neumann G, Römheld V: Root excretion of carboxylic acids and protons in phosphorus-deficient plants. Plant Soil 1999, 211:121-130

10. Ma JF, Ryan PR, Delhaize E: Aluminium tolerance in plants and the complexing role of organic acids. Trends Plant Sci 2001, 6:273-278.

11. Vance $C P$, Unde-Stone $C$, Allan DL: Phosphorus acquisition and use: critical adaptations by plants for securing a nonrenewable resource. New Phytol 2003, 157:423-447.

12. Richardson AE, Lynch JP, Ryan PR, Delhaize E, Smith FA, Smith SE, Harvey $P R$, Ryan MH, Veneklaas EJ, Lambers H, Oberson A, Culvenor RA, Simpson RJ. Plant and microbial strategies to improve the phosphorus efficiency of agriculture. Plant Soil 2011, 349:121-156.

13. Delhaize E, Taylor P, Hocking PJ, Simpson RJ, Ryan PR, Richardson AE: Transgenic barley (Hordeum vulgare L.) expressing the wheat aluminium resistance gene (TaALMT1) shows enhanced phosphorus nutrition and grain production when grown on an acid soil. Plant Biotechnol J 2009, 7:391-400.

14. Wang Y, Xu H, Kou J, Shi L, Zhang C, Xu F: Dual effects of transgenic Brassica napus overexpressing CS gene on tolerances to aluminum toxicity and phosphorus deficiency. Plant Soil 2013, 362:231-246.
15. Liang C, Piñeros MA, Tian J, Yao Z, Sun L, Liu J, Shaff J, Coluccio A, Kochian $\mathrm{LV}$, Liao $\mathrm{H}$ : Low $\mathrm{pH}$, aluminum, and phosphorus coordinately regulate malate exudation through GmALMT1 to improve soybean adaptation to acid soils. Plant Physiol 2013, 161:1347-1361.

16. Nian H, Ahn SJ, Yang ZM, Matsumoto H: Effect of phosphorus deficiency on aluminium-induced citrate exudation in soybean (Glycine max). Physiol Plant 2003, 117:229-236

17. Dong $D$, Peng $X$, Yan $X$ : Organic acid exudation induced by phosphorus deficiency and/or aluminium toxicity in two contrasting soybean genotypes. Physiol Plant 2004, 122:190-199.

18. Ligaba A, Shen H, Shibata K, Yamamoto Y, Tanakamaru S, Matsumoto H: The role of phosphorus in aluminium-induced citrate and malate exudation from rape (Brassica napus). Physiol Plant 2004, 120:575-584.

19. Liao H, Wan H, Shaff J, Wang X, Yan X, Kochian LV: Phosphorus and aluminum interactions in soybean in relation to aluminum tolerance: exudation of specific organic acids from different regions of the intact root system. Plant Physiol 2006, 141:674-684.

20. Elshire RJ, Glaubitz JC, Sun Q, Poland JA, Kawamoto K, Buckler ES, Mitchell SE: A Robust, Simple Genotyping-by-Sequencing (GBS) approach for high diversity species. PLOS One 2011, 6:e19379.

21. Aulchenko YS, Ripke $S$, Isaacs A, Van Duijn CM: GenABEL: an R library for genome-wide association analysis. Bioinformatics 2007, 23:1294-1296.

22. Caniato FF, Hamblin MT, Guimaraes CT, Zhang Z, Schaffert RE, Kochian LV, Magalhaes JV: Association mapping provides insights into the origin and the fine structure of the sorghum aluminum tolerance locus, AltSB. PLOS ONE 2014, 9:e87438

23. Valluru R, Vadez V, Hash CT, Karanam P: A minute P application contributes to a better establishment of pearl millet (Pennisetum glaucum (L.) R. Br.) seedling in P deficient soils. Soil Use Manag 2010, 26:36-43.

24. Leiser WL, Rattunde HFW, Weltzien E, Haussmann BIG: Phosphorus uptake and use efficiency of diverse West and Central African sorghum genotypes under field conditions in Mali. Plant Soil 2014, 377:383-394

25. Atlin GN, Frey KJ: Predicting the relative effectiveness of direct versus indirect selection for oat yield in three types of stress environments. Euphytica 1989, 44:137-142.

26. Beebe S, Lynch J, Galwey N, Tohme J, Ochoa I: A geographical approach to identify phosphorus-efficient genotypes among landraces and wild ancestors of common bean. Euphytica 1997, 95:325-338.

27. Hammond JP, Broadley MR, White PJ, King GJ, Bowen HC, Hayden R, Meacham MC, Mead A, Overs T, Spracklen WP, Greenwood DJ: Shoot yield drives phosphorus use efficiency in Brassica oleracea and correlates with root architecture traits. J Exp Bot 2009, 60:1953-1968.

28. Parentoni S, de Souza C Jr, de Carvalho Alves V, Gama E, Coelho A, de Oliveira A, Guimarães P, Guimarães C, Vasconcelos M, Pacheco CAP, Meirelles WF, de Magalhães JV, Moreira Guimarães $L$, da Silva AR, Ferreira Mendes F, Schaffert RE: Inheritance and breeding strategies for phosphorus efficiency in tropical maize (Zea Mays L.). Maydica 2010, 55:1-15.

29. Ding G, Zhao Z, Liao Y, Hu Y, Shi L, Long Y, Xu F: Quantitative trait loci for seed yield and yield-related traits, and their responses to reduced phosphorus supply in Brassica napus. Ann Bot 2012, 109:747-759.

30. Deu M, Sagnard F, Chantereau J, Calatayud C, Hérault D, Mariac C, Pham J-L, Vigouroux Y, Kapran I, Traore PS, Mamadou A, Gerard B, Ndjeunga J, Bezançon G: Niger-wide assessment of in situ sorghum genetic diversity with microsatellite markers. Theor Appl Genet 2008, 116:903-913.

31. Sagnard F, Deu M, Dembélé $D$, Leblois R, Touré L, Diakité M, Calatayud C, Vaksmann M, Bouchet S, Mallé Y, Togola S, Traoré PCS: Genetic diversity, structure, gene flow and evolutionary relationships within the Sorghum bicolor wild-weedy-crop complex in a western African region. Theor Appl Genet 2011, 123:1231-1246.

32. Billot C, Ramu P, Bouchet S, Chantereau J, Deu M, Gardes L, Noyer J-L, Rami J-F, Rivallan R, Li Y, Lu P, Wang T, Folkertsma RT, Arnaud E, Upadhyaya HD, Glaszmann J-C, Hash CT: Massive sorghum collection genotyped with SSR markers to enhance use of global genetic resources. PLoS One 2013, 8:e59714.

33. Bouchet S, Pot D, Deu M, Rami J-F, Billot C, Perrier X, Rivallan R, Gardes L, Xia L, Wenzl P, Kilian A, Glaszmann J-C: Genetic structure, linkage disequilibrium and signature of selection in sorghum: lessons from physically anchored DArT markers. PLoS One 2012, 7:e33470.

34. Morris GP, Ramu P, Deshpande SP, Hash CT, Shah T, Upadhyaya HD, Riera-Lizarazu O, Brown PJ, Acharya CB, Mitchell SE, Harriman J, Glaubitz JC, 
Buckler ES, Kresovich S: Population genomic and genome-wide association studies of agroclimatic traits in sorghum. Proc Natl Acad Sci 2013, 110:453-458.

35. Barro-Kondombo C, Sagnard F, Chantereau J, Deu M, Vom Brocke K, Durand P, Gozé E, Zongo JD: Genetic structure among sorghum landraces as revealed by morphological variation and microsatellite markers in three agroclimatic regions of Burkina Faso. Theor App/ Genet 2010, 120:1511-1523.

36. Mace ES, Tai S, Gilding EK, Li Y, Prentis PJ, Bian L, Campbell BC, Hu W, Innes DJ, Han X, Cruickshank A, Dai C, Frère C, Zhang H, Hunt CH, Wang X, Shatte T, Wang M, Su Z, Li J, Lin X, Godwin ID, Jordan DR, Wang J: Whole-genome sequencing reveals untapped genetic potential in Africa's indigenous cereal crop sorghum. Nat Commun 2013, 4:1-9.

37. Rattunde HFW, Weltzien E, Diallo B, Diallo AG, Sidibe M, Touré AO, Rathore A, Das RR, Leiser WL, Touré A: Yield of photoperiod-sensitive sorghum hybrids based on Guinea-race germplasm under farmers' field conditions in Mali. Crop Sci 2013, 53:2454

38. Voortman RL, Brouwer J, Albersen PJ: Characterization of spatial soil variability and its effect on millet yield on Sudano-Sahelian coversands in SW Niger. Geoderma 2004, 121:65-82.

39. Manu A, Wilding LP, Hossner LR, Pfordresher AA, Geiger SC: Soil parameters related to crop growth variability in Western Niger, West Africa. Soil Sci Soc Am J 1996, 60:283-288.

40. Melo JO, Lana UGP, Piñeros MA, Alves VMC, Guimarães CT, Liu J, Zheng Y, Zhong S, Fei Z, Maron LG, Schaffert RE, Kochian LV, Magalhaes JV: Incomplete transfer of accessory loci influencing SbMATE expression underlies genetic background effects for aluminum tolerance in sorghum. Plant J 2013, 73:276-288.

41. luchi S, Koyama H, luchi A, Kobayashi Y, Kitabayashi S, Kobayashi Y, Ikka T, Hirayama T, Shinozaki K, Kobayashi M: Zinc finger protein STOP1 is critical for proton tolerance in Arabidopsis and coregulates a key gene in aluminum tolerance. Proc Natl Acad Sci 2007, 104:9900-9905.

42. Kobayashi Y, Ohyama Y, Kobayashi Y, Ito H, luchi S, Fujita M, Zhao C-R, Tanveer T, Ganesan M, Kobayashi M, Koyama H: STOP2 activates transcription of several genes for $\mathrm{Al}$ - and low $\mathrm{pH}$-tolerance that are regulated by STOP1 in Arabidopsis. Mol Plant 2014, 7:311-322.

43. Ohyama Y, Ito H, Kobayashi Y, Ikka T, Morita A, Kobayashi M, Imaizumi R, Aoki T, Komatsu K, Sakata Y, luchi S, Koyama H: Characterization of AtSTOP1 orthologous genes in tobacco and other plant species. Plant Physiol 2013, 162:1937-1946.

44. Thibaud M-C, Arrighi J-F, Bayle V, Chiarenza S, Creff A, Bustos R, Paz-Ares J, Poirier $Y$, Nussaume L: Dissection of local and systemic transcriptional responses to phosphate starvation in Arabidopsis. Plant J 2010, 64:775-789

45. Valdés-López $\mathrm{O}$, Hernández G: Transcriptional regulation and signaling in phosphorus starvation: what about legumes? J Integr Plant Biol 2008, 50:1213-1222.

46. Jung YJ, Lee IH, Nou IS, Lee KD, Rashotte AM, Kang KK: BrRZFP1 a Brassica rapa C3HC4-type RING zinc finger protein involved in cold, salt and dehydration stress. Plant Biol 2013, 15:274-283.

47. Caniato FF, Guimarães CT, Hamblin M, Billot C, Rami JF, Hufnagel B, Kochian LV, Liu J, Garcia AAF, Hash CT: The relationship between population structure and aluminum tolerance in cultivated sorghum. PLoS One 2011, 6:e20830.

48. Walton JD: HC-toxin. Phytochemistry 2006, 67:1406-1413.

49. Sugawara F, Strobel G, Strange RN, Siedow JN, Duyne GDV, Clardy J: Phytotoxins from the pathogenic fungi Drechslera maydis and Drechslera sorghicola. Proc Natl Acad Sci 1987, 84:3081-3085.

50. Sindhu A, Chintamanani S, Brandt AS, Zanis M, Scofield SR, Johal GS: A guardian of grasses: specific origin and conservation of a unique disease-resistance gene in the grass lineage. Proc Natl Acad Sci 2008, 105:1762-1767.

51. Mohnen D: Pectin structure and biosynthesis. Curr Opin Plant Biol 2008, 11:266-277.

52. Lam E: Controlled cell death, plant survival and development. Nat Rev Mol Cell Biol 2004, 5:305-315.

53. Roberts IN, Caputo C, Criado MV, Funk C: Senescence-associated proteases in plants. Physiol Plant 2012, 145:130-139.

54. Bray R, Kurtz LT: Determination of total, organic, and available forms of phosphorus in soils. Soil Sci 1945, 59:39-46.

55. Leiser WL, Rattunde HF, Piepho H-P, Parzies HK: Getting the most out of sorghum low-input field trials in West Africa using spatial adjustment. J Agron Crop Sci 2012, 198:349-359.
56. Cullis $B R$, Smith $A B$, Coombes NE: On the design of early generation variety trials with correlated data. J Agric Biol Environ Stat 2006, 11:381-393.

57. Yan W, Kang MS: GGE Biplot Analysis: A Graphical Tool for Breeders, Geneticists, and Agronomists. 1st edition. Boca Raton: CRC Press; 2002

58. Bradbury PJ, Zhang Z, Kroon DE, Casstevens TM, Ramdoss Y, Buckler ES: TASSEL: software for association mapping of complex traits in diverse samples. Bioinformatics 2007, 23:2633-2635.

59. Paterson AH, Bowers JE, Bruggmann R, Dubchak I, Grimwood J, Gundlach H, Haberer G, Hellsten U, Mitros T, Poliakov A, Schmutz J, Spannagl M, Tang H, Wang X, Wicker T, Bharti AK, Chapman J, Feltus FA, Gowik U, Grigoriev IV, Lyons E, Maher CA, Martis M, Narechania A, Otillar RP, Penning BW, Salamov AA, Wang Y, Zhang L, Carpita NC, et al: The Sorghum bicolor genome and the diversification of grasses. Nature 2009, 457:551-556.

60. Roberts A, McMillan L, Wang W, Parker J, Rusyn I, Threadgill D: Inferring missing genotypes in large SNP panels using fast nearest-neighbor searches over sliding windows. Bioinformatics 2007, 23:i401-i407.

61. Shin J-H, Blay S, McNeney B, Graham J: LDheatmap: an R function for graphical display of pairwise linkage disequilibria between single nucleotide polymorphisms. J Stat Softw 2006, 16:1-9.

62. Zheng X, Levine D, Shen J, Gogarten SM, Laurie C, Weir BS: A High-performance Computing Toolset for Relatedness and Principal Component Analysis of SNP Data. Bioinformatics 2012, 28:3326-3328.

63. Alexander DH, Novembre J, Lange K: Fast model-based estimation of ancestry in unrelated individuals. Genome Res 2009, 19:1655-1664

64. Lipka AE, Tian F, Wang Q, Peiffer J, Li M, Bradbury PJ, Gore MA, Buckler ES, Zhang Z: GAPIT: genome association and prediction integrated tool. Bioinformatics 2012, 28:2397-2399.

65. Zhang Z, Ersoz E, Lai C-Q, Todhunter RJ, Tiwari HK, Gore MA, Bradbury PJ, Yu J, Arnett DK, Ordovas JM, Buckler ES: Mixed linear model approach adapted for genome-wide association studies. Nat Genet 2010, 42:355-360.

\section{doi:10.1186/s12870-014-0206-6}

Cite this article as: Leiser et al:: Two in one sweep: aluminum tolerance and grain yield in P-limited soils are associated to the same genomic region in West African Sorghum. BMC Plant Biology 2014 14:206.

\section{Submit your next manuscript to BioMed Central and take full advantage of:}

- Convenient online submission

- Thorough peer review

- No space constraints or color figure charges

- Immediate publication on acceptance

- Inclusion in PubMed, CAS, Scopus and Google Scholar

- Research which is freely available for redistribution 